\title{
Sudden Proximal Femoral Fracture on 7-Years-Old- Boy Poliostotic Fibrous Dysplasia and Mccune Albright Syndrome
}

\author{
Daniel Godoy-Monzon ${ }^{1,2^{*}}$, Jose Manuel Pascual-Espinosa ${ }^{2}$, Angel Gonzalez- \\ Fernandez ${ }^{2}$, Esther Fernandez-Sainz Rozas ${ }^{2}$ and Juan Jimenez-Baquero ${ }^{2}$ \\ ${ }^{1}$ Orthopedic and Traumatology Service, Hospital Italiano de Buenos Aires, Argentina \\ ${ }^{2}$ Orthopedic and Traumatology Service, Hospital Santa Maria del Puerto, España
}

\begin{abstract}
Introduction: Fibrous Dysplasia is a rare condition, affecting one (monostotic) or several bones (polyostotic) characterized by fibro osseous tissue in the bone causing pain, deformities and sometimes pathologic fractures. It is a result of a mutation in the GNAS that can have manifestation in different systems conforming a complex syndrome named McCune Albright (fibrous dysplasia, café au lait skin hyper pigmentation and endocrinopathies.

Case report: A 7-years-old boy, presented at emergency unit due to sudden pain and limping without trauma. Radiographic evaluation showed a fractured proximal femur, within an unknow cist, and multiple lesions on tibia and fibula. During pediatric assessment a skin café e lait patch was observed, and a genetic profile was performed with a general screening detecting lesion on skull, mandibula. The fracture was treated by curettage, bone grafting and plating.

Conclusion: By assessing the patient in an interdisciplinary team, we treated successfully the proximal femur fracture and detected a rare and complex syndrome. A review of the orthopaedic treatment options showed a lack of guidelines so the idea of patients tailored surgery is the best option.
\end{abstract}

\section{Keywords}

Proximal Femur Fracture, Fibrous Dysplasia, Mccunne Albright Syndrome

\section{Introduction}

Fibrous Dysplasia (FD) has a wide variation in orthopedic presentation from deformities to fractures. There are 2 types: Monostotic (involving any bone) or polyostotic (affecting many parts of the skeleton) and sometimes discovered incidentally. The pathology is based on the presence of fibrous osseous tissue with widening and thinning of the cortical bone, as result of an post zygotic mutation of GNAS, if involving multiple systems like skin, skeleton, and endocrine system is defined as McCune-Albright syndrome [1,2]. The incidence of this rare syndrome is not clear and different reports present $1 / 100000$ to $1 / 1000000$ prevalence [3].

When FD compromise the proximal femur there are some indicative symptoms like pain, limping, pathological fractures, deformity (shepherds crook), and a high recurrence and treatment failure rate. As there is an infrequent condition with no definitive treatment guidelines and a wide range of age presentation, case tailored surgery is the best option [4].

There area multiple treatment options proposed: Prophylactic curettage and bone grafting, fixation if fracture plus grafting using plates or cephalomedullar nails.

\section{Case Report}

7-years-old boy assisted at emergency unit due to sudden pain and limping without any trauma history. No other comorbilities were detected initially, the patient was born with no incidents during pregnancy with a weight of $3500 \mathrm{~g}$ and a height of $47 \mathrm{cms}$. During exam the parents related the patient presented two previous episodes of limping that were transient (couple of days) and solved with rest and Ibuprofen.

*Corresponding author: Daniel Godoy-Monzon, Orthopedic and Traumatology Service, Hospital Italiano de Buenos Aires, Buenos Aires, Argentina

Accepted: November 28, 2020

Published online: November 30, 2020

Citation: Godoy-Monzon D, Pascual-Espinosa JM, GonzalezFernandez A, et al. (2020) Sudden Proximal Femoral Fracture on 7-Years-Old-Boy Poliostotic Fibrous Dysplasia and Mccune Albright Syndrome. Adv Tech Musculoskelet Surg 4(2):46-49 


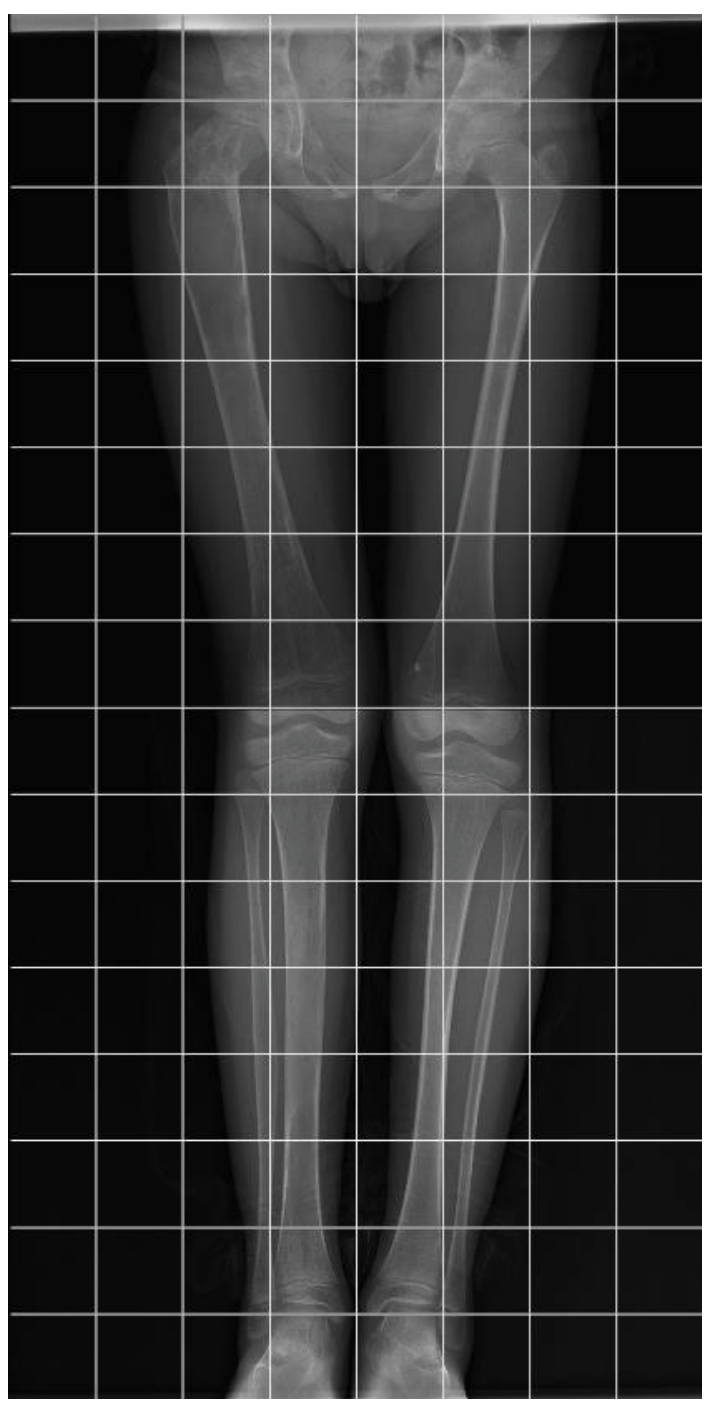

Figure 1: Initial anteroposterior both limbs xray were the femoral cist and tibial cist were detected.

Radiographic evaluation detected a proximal femoral fracture with minimal displacement on an unknown cist (presenting irregular trabecular pattern with areas of increase density and thinning of cortical bone) (Figure 1), and other FD focus on the tibia and fibula. Scintigraphy showed multiple lesions on the skeleton (Figure 1).

The patient was admitted and orthopedic service consulted to define treatment. Until this moment the patient presented only FD. During preoperative clinical evaluation a minimal light brown patch cafe au lait like was noted, and the parents referred it was present since birth, and a consult due to low growth percentile have been done, full body scanning detected skull, tibia, femur and mandibula involvement; after clinical debate the pediatricians decided to perform a genetic analysis resulting as a McCune Albright syndrome, and completed an endocrinology screening.

After informed consent signed by the parents responsable for the patient, the orthopedic team performed on the proximal femur fracture a surgery with bone grafting (combining morsalized and structural bone) and plating (Figure $2 \mathrm{~A}$ and

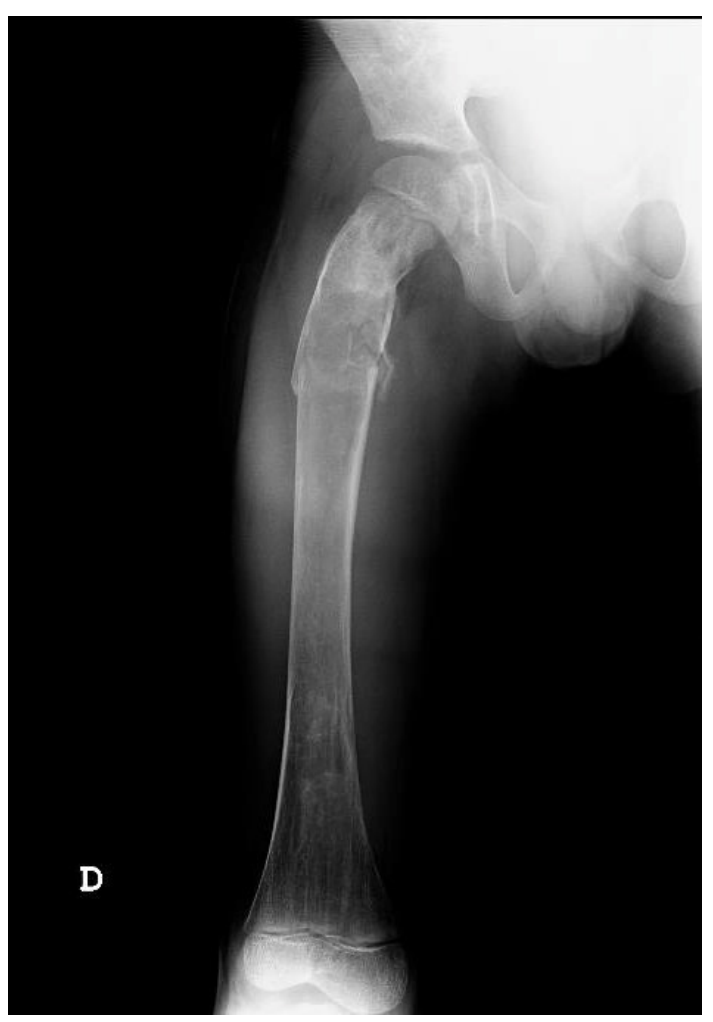

Figure 2A: Anteroposterior and lateral xrays of femur, showing the fibrous dysplasia and an undisplaced fracture through the cist.

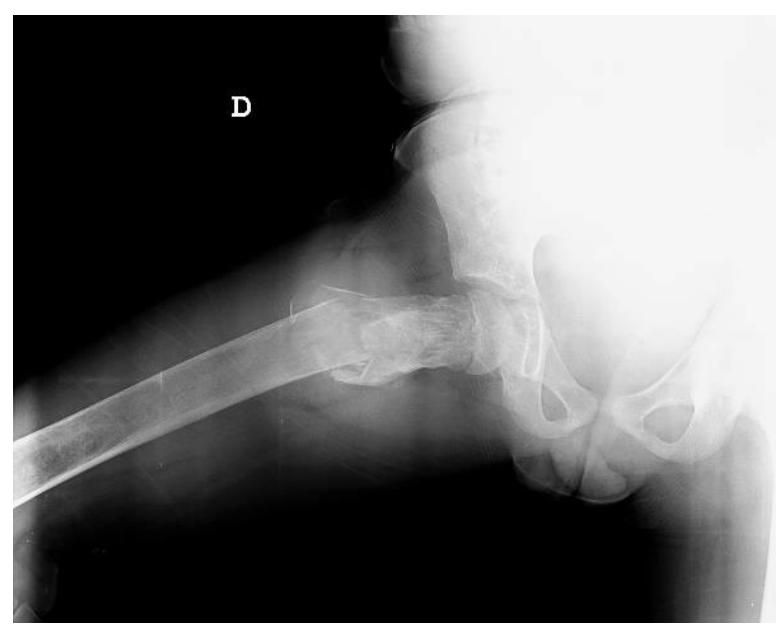

Figure 2B: Anteroposterior and lateral xrays of femur, showing the fibrous dysplasia and an undisplaced fracture through the cist.

Figure 2B).

During follow up the patient had a good functional and radiographic evolution with fracture consolidation and bone graft incorporation at 3 months (Figure $3 \mathrm{~A}$ and Figure $3 \mathrm{~B}$ ) and return to normal life after 6 months (Figure 4A, and Figure 4B).

\section{Discussion}

There is still a debate about the treatment of lesions as the one our patient presented. We decided to use curettage, 


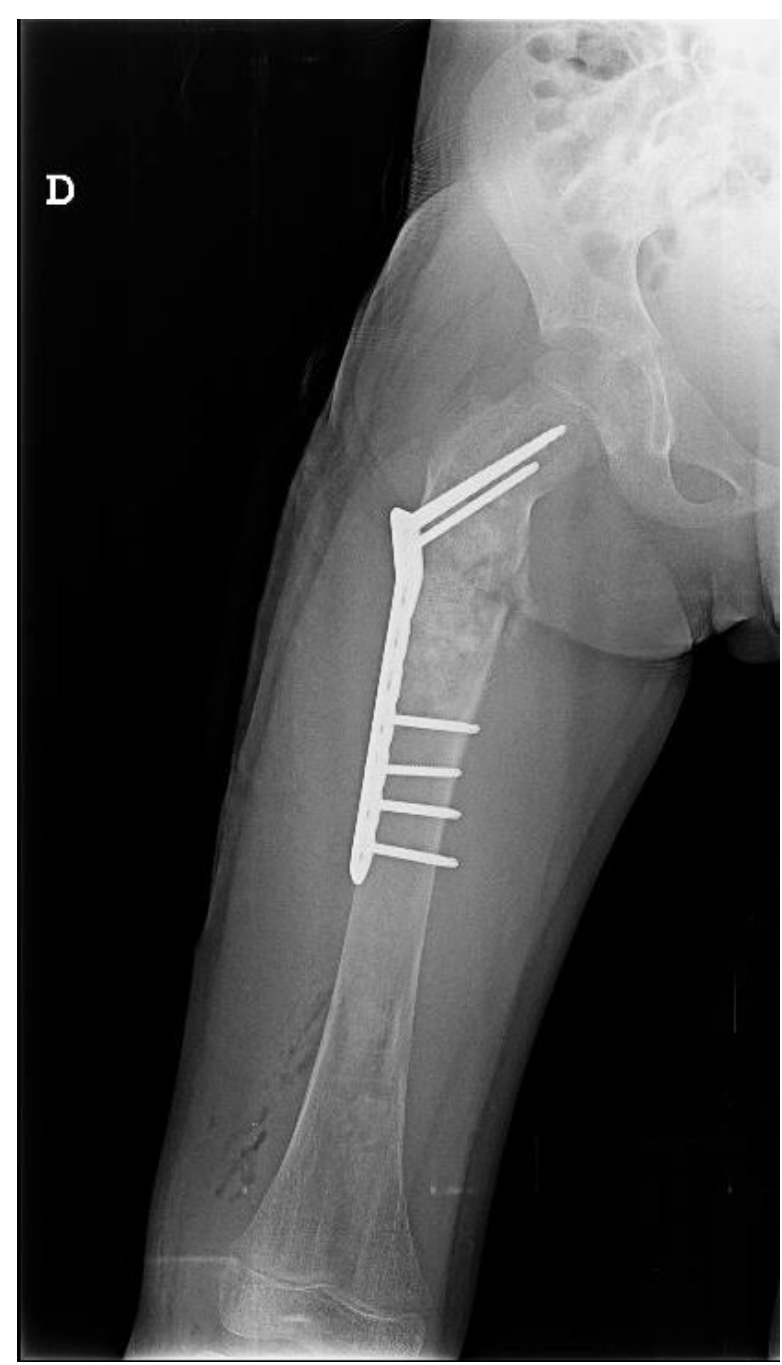

Figure 3A: Anteroposterior and lateral xrays of femur, showing the surgery result of curettage, bone grafting and plating on the fracture.

bone graft and internal fixation with good functional and radiographic result.

Some authors use synthetic bone substitute with the advantage of simple technique, bone induction properties and no donor site. There is a lack of information about long term function of the bone. The non vascularized fibular bone graft may be an option, but complications as nerve palsy, bleeding and residual deformation and even stress fractures in an patient with growing physis can be an important limitation. There is concern due to long period of weight bearing limitation caused by donor site damage and intralesional bone graft incorporation, making this technique not common $[5,6]$.

Autologous cancellous bone graft offer several advantages as fast incorporation with revascularization and no immunogenic response, but is limited amount to fill large bone defect as presented in our case, may present bleeding as complication. It has been reported a high failure rate of $48 \%$ due to not adequate load transfer and support [5-7].

We decided to use allograft based on the availability of bone bank, the extension of the lesion, demanding a huge

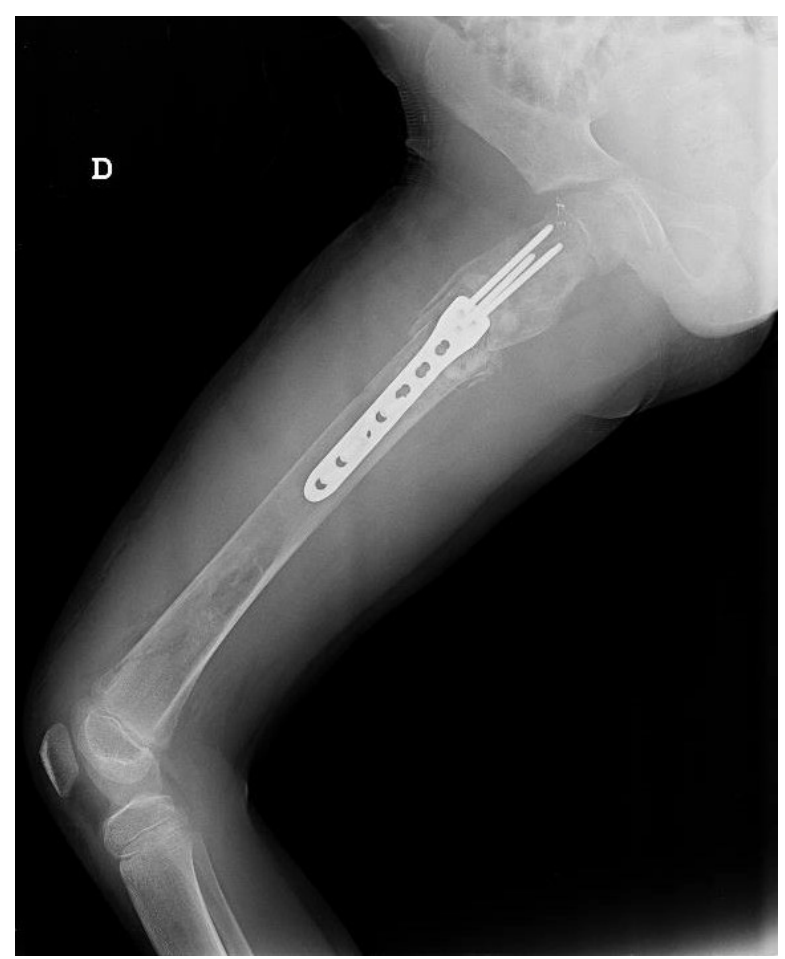

Figure 3B: Anteroposterior and lateral xrays of femur, showing the surgery result of curettage, bone grafting and plating on the fracture 3B.

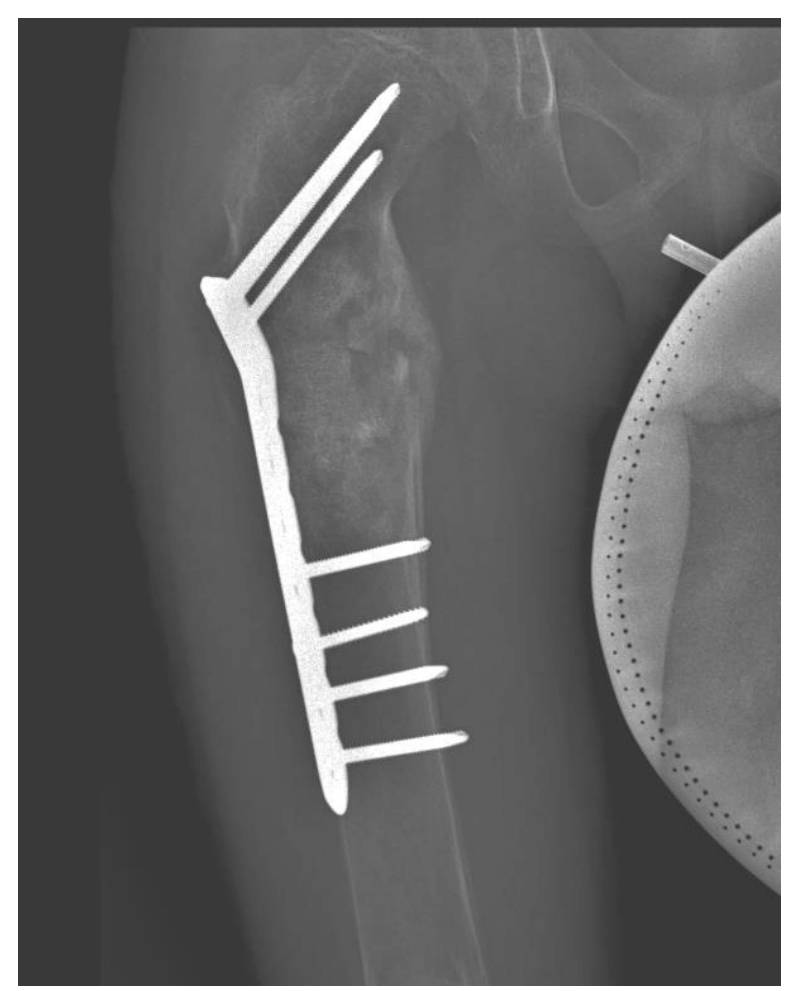

Figure 4A: Anteroposterior and lateral xrays of femur, showing good bone graft osteointegration and fracture consolidation.

amount of graft and the combination of morsalized and structural material, allowing fast incorporation and structural support $[7,8]$. 
Citation: Godoy-Monzon D, Pascual-Espinosa JM, Gonzalez-Fernandez A, et al. (2020) Sudden Proximal Femoral Fracture on 7-Years-Old-Boy Poliostotic Fibrous Dysplasia and Mccune Albright Syndrome. Adv Tech Musculoskelet Surg 4(2):46-49

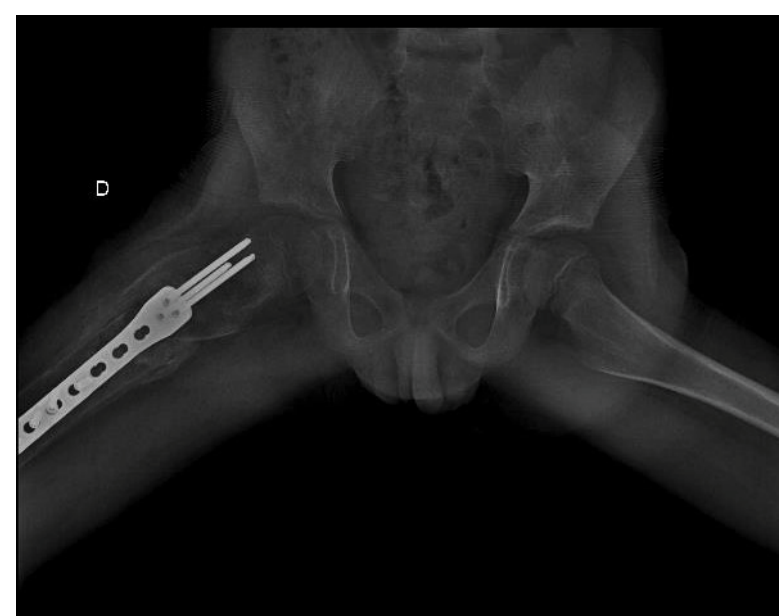

Figure 4B: Anteroposterior and lateral xrays of femur, showing good bone graft osteointegration and fracture consolidation.

The lateral approach allowed us to work directly on the lesion, with a window for curettage and grafting. The internal fixation with a low contact dynamic plate gave us the advantage of strong fixation on the femoral neck without lesion of the physis and bypass the lesion giving compression on the grafted zone. Similar technique was described with success by Nakamura on 13 patients with one superficial infection and one chronic muscular pain with implant removal after 7 years from index surgery [9].

\section{Conclusion}

Polyostotic fibrous dysplasia is not a frequent pathology, and its association with a genetic syndrome may be a diagnosis in young patients who suffer unexpected fractures at daily activities.

Team focus is needed to identify the complex syndrome and tailored treatment should be done with high level of resources as bone bank, trauma specialists, and multiple fixation devices.

The work was done at Orthopedic and Traumatology Ser- vice, Hospital Santa Maria del Puerto, Puerto de Santa Maria, España

\section{Funding}

No source of financial support was received.

\section{Conflicts of Interest}

The authors have no conflicts of interest related to the actual article.

\section{References}

1. DiCaprio MR, Ennecking WF (2005) Fibrous dysplasia. Pathophysiology, evaluation, and treatment. J Bone Joint Surg Am 87: 1848-1864.

2. Shenker A, Weinstein LS, Sweet DE, et al. (1994) An activating ds alpha mutations of the stimulatory gprotein in the mccune albright syndrome. J Clin Endocrinol Metab 79: 750-755.

3. Dumitrescu ED, Collins MT (2008) Mccune- albright syndrome. Orphanet J Rare Dis 3: 12.

4. Guille JT, Kumar SJ, Mac Ewen GD, et al. (1998) Fibrous dysplasi of the proximal part of the femur. long temn results of curettage and bone grafting and mechanical realignment. J Bone Joint Surg Am 80: 648-658.

5. George B, Abudu A, Grimer RJ, et al. (2008) The treatment of benign lesions of the proximal femur with non-vascularised autologousfibular strut grafts. J Bone Joint Surg 90: 648-651.

6. Rafalla A, Elsheikh M (2014) Use of an autologous neovascularized fibular strutgraft in the treatment of benign cystic lesions of the proximal femur. Egypt Orthop J 49: 220-224.

7. Enneking WF, Gearen PF (1986) Fibrous dysplasia of the femoral neck; Treatmentby cortical bone grafting. J Bone Joint Surg Am 68: 1415-1422.

8. Mankin HJ, Gebhardt MC, Jennings LC, et al. (1996) Long-term results of allograft replacement in the management of bone tumors. Clin Orthop 324: 86-97.

9. Nakamura T, Matsumine A, Asanuma K, et al. (2015) Treatment of the benign bone tumors including femoral neck lesion using compression hip screw and synthetic bone graft. SICOT J 1: 15.

DOI: $10.36959 / 765 / 396$

Copyright: () 2020 Godoy-Monzon, et al. This is an open-access article distributed under the terms of the Creative Commons Attribution License, which permits unrestricted use, distribution, and reproduction in any medium, provided the original author and source are credited. 